\title{
HOW TO SURVIVE TRANSITIONING FROM BLACKBOARD TO MOODLE: 12 SURVIVAL TIPS
}

\author{
Lori Soule, Nicholls State University, lori.soule@nicholls.edu \\ Betty A. Kleen, Nicholls StateUniversity, betty.kleen@nicholls.edu
}

\begin{abstract}
This paper presents steps one university took during the implementation stage of a new course management system. To cut costs instead of cutting faculty, the university switched from Blackboard to Moodle. Literature related to both the Technology Acceptance Model and organizational change models provided important considerations regarding implementation, end user concerns and system adoption. At the time of the switch, the authors' institution faced the additional challenge of very limited budget in a time of severe financial constraints to accomplish faculty conversion to Moodle. In this paper the authors present 12 tips that helped the university implement Moodle within a 12-month timeframe on a "shoestring" budget, along with personal experiences and comments regarding the value of the steps.
\end{abstract}

Keywords: Course Management Systems; Technology Acceptance; Change Management; Software Adoption

\section{INTRODUCTION}

More and more universities are facing the reality of reducing spending due to budget cuts. Some universities are attempting to cut costs rather than making additional reductions to faculty and/or staff numbers. One area in which universities can cut costs is through the changing of their course management system (CMS). For example, although Blackboard is a very popular CMS, Moodle is an open-source CMS, and for the most part, is free.

Although some universities may have the luxury of several support and/or instructional staff with teaching experience available to assist faculty with effective use of the school's CMS, other schools may have little or no structured assistance. The authors' university is one of the latter. One faculty member has a half-time reduction in fall and spring semesters and a zero teaching load in the summer and is responsible for running the Center for the Advancement of Faculty Engagement, referred to as the CAFÉ. As one part of the CAFÉ administration, the faculty member is the only officially designated support person working with faculty for any CMS upgrades or software switches. (This faculty member is one of the two authors of this paper.)

University faculty are experiencing ever increasing student assessment and retention expectations; coupled with a scenario of no raises in a number of years and low morale, it is also very unlikely that extremely high percentages of faculty would rush to adopt the new system or plan to attend extensive training even if it were offered. Within the constraints of the limited instructional support described above, however, the authors' university has managed to move through a successful CMS conversion in a little over a year. The authors share a dozen support steps completed on a "shoestring" budget.

\section{LEARNING FROM THE TECHNOLOGY ACCEPTANCE MODEL AND ORGANIZATIONAL CHANGE LITERATURE}

Davis's [5] Technology Acceptance Model (TAM) has provided a theoretical basis used in numerous research studies since the 1980s, including those of researchers such as Agarwal \& Prasad [1], Brown [3], Davis, Bagozzi, \& Warsha [6], Halawi \& McCarthy [8], Schepers \& Wetzels [11], and Venkatesh [13]. Although findings are not totally consistent in all the studies, ease of system use and perceived usefulness of a system relationships are supported in numerous studies. Schepers \& Wetzels' 2006 meta-analysis of the Technology Acceptance Model concluded that differences in research setting may affect results, but overall original TAM relationships remain confirmed [11]. 


\section{Issues in Information Systems}

Volume 13, Issue 2, pp. 209-218, 2012

White \& Myers [14] reported faculty as identifying planning as the issue of highest concern when delivering instruction through a CMS. Within the planning dimension, the tasks of learning the new software and converting and uploading course data were specifically identified. Tabata and Johnsrud [12] found faculty participation in distance education is in part associated with their skill in using technology. In researching faculty members' perceptions regarding their teaching efficacy, Chang, Lin, \& Song [4] found that technology usage was next to the bottom in six dimensions of teaching effectiveness, with course design, class management, interpersonal relations, and learning assessment all ranking higher. Only instructional strategy had a lower mean score. This lower efficacy in technology usage could suggest that a university can expect challenges and faculty resistance when making significant software changes such as introducing a new CMS.

Orr, Williams, and Pennington, studying institutional efforts to support faculty in online teaching, note the value of strategic communication concerning online education and found it to offer the greatest potential for institutional improvement in their study [10]. Switching to a different CMS is a significant organizational change in the eyes of faculty (and often for students, as well). Thus it is logical that faculty need to understand how the switch of course management systems fits into the strategic direction of the institution.

Researching faculty adoption of a course management system in a university environment, Halawi and McCarthy [8] found that faculty will use a CMS such as Blackboard if it is perceived to be useful, if it is perceived as easy to use, and if it supports their needs. Baker-Eveleth \& Stone [2] studied faculty users in a new software implementation of Digital Measures and found that previous computer experience, ease of system use, and administrator support were linked to behavioral intentions of faculty to use the software.

Lee and Busch [9] identified that adequate training is related to faculty willingness to participate in distance education, which typically involves use of a CMS. Orr, Williams, and Pennington [10] found workshops and oneto-one support are important in the eyes of faculty. Brown [3] also found training is very important and an effective predictor of personal initiative, as well as a predictor of use and perceived usefulness.

Fedorowicz, Gelinas, Usoff, and Hachey's suggestions related to integrating an enterprise system across the curriculum also have application when introducing a new CMS to faculty in an institution [7]. They recommended practicing knowledge diffusion, not reinventing the wheel, having realistic expectations, providing good customer support, and making sure that users have illustrations (also interpreted as satisfying the needs of those who ask, "but what does it really look like").

While much of the above research has focused specifically on the technology acceptance from the TAM or another modification within the information systems literature, Brown's 2009 study related to replacement of a legacy IT system at a university looked at the switch from the perspectives of both organizational change models and the TAM [3]. Perceived ease of use, perceived usefulness, and change efficacy were predictors of personal initiative concerning accepting the new system. Brown further noted, "perceptions of new technology are tied to perceptions of the change agents' management of the implementation process, as well as the ramifications of the organizational change on the organization as a whole." He further suggests that change agents, "should be wary of thinking that a new technology can 'sell itself' to the change recipients."

By considering what the literature tells us about implementing new technology within a university environment with faculty as end users of the system, the authors' institution focused on educating the faculty on the need for the change, presenting the change as easy to learn and easy to use, providing plenty of training at whatever level an instructor chose and whatever the learning style preference, and having realistic expectations in adoption speed. The institution recognized that the technology would not sell itself to every faculty member and that effective management of the implementation process would be important in influencing faculty perceptions of the change. 


\section{Issues in Information Systems}

Volume 13, Issue 2, pp. 209-218, 2012

\section{THE PROJECTED TIMELINE FOR CONVERTING FROM BLACKBOARD TO MOODLE}

During the fall of 2010, central administration at the authors' university decided to move from Blackboard (version 8) to Moodle (version 1.9). This transition began in spring 2011 when IT staff began the installation work; the established goal was that all faculty would be fully converted to Moodle and Blackboard totally removed by summer 2012. During the spring 2011 semester, one server was set up and loaded with Moodle 1.9. This server was designated as the "Sandbox." In the Sandbox, instructors were able to create classes, add content to the created classes, and test the different components of Moodle without having the worry of students accessing these courses. While only a very small number participated in the Sandbox during spring 2011, more started "playing" over the summer. In August 2011, the "Production" server was installed and loaded with the same compile version of Moodle that was loaded for the Sandbox. The Production server contained course sections that were accessible by students. The Moodle version was "very vanilla" with the only add-in being Quickmail v2.5. Thus early adopters could use Moodle as their CMS in the fall if they so desired. Those later adopters simply continued using Blackboard during that semester.

\section{SURVIVAL STEPS ON A SHOESTRING BUDGET}

While the authors recognize that the university did not achieve $100 \%$ of the faculty moving to the new system without some serious objection and dragging of feet, the list below details an overall approach that allowed the institution to complete its Moodle conversion more quickly than another university only 70 miles away. Each of the items in this list is discussed in the sections that follow.

1. Determine similarities and differences between the new CMS and the previous CMS

2. Update and educate key faculty committees even before the system is available for early adopters

3. Create help sheets for popular tasks

4. Create a Moodle course section that contains help sheets

5. Offer workshops in the semester prior to the implementation

6. Pilot Moodle with volunteers

7. Trouble-shoot and solve problems in a speedy manner

8. Create additional help sheets as problems arise

9. Send email with help sheet attachments of beginning-of-semester and end-of-semester tasks

10. Reiterate to faculty to export Moodle grades to a spreadsheet such as Excel to check grade calculations through the spreadsheet before assigning final grades for the term

11. Offer small-group help with grades at mid-term and end-of-semester

12. Remain courteous, jovial, and accepting of faculty thanks

\section{Determine Similarities and Differences between the New CMS and the Previous CMS}

Most of the faculty were already acquainted and had adjusted to using Blackboard as their CMS. Even though a faculty member might still be teaching face-to-face classes only, all were required, at minimum, to post syllabi and grades on Blackboard. So in order to reduce confusion when moving to Moodle, similarities between Blackboard and Moodle were emphasized. Table 1 lists key similarities such as announcements, forums, and activities faculty would commonly use in their courses. 


\section{Issues in Information Systems}

Volume 13, Issue 2, pp. 209-218, 2012

Table 1. Blackboard-Moodle Similarities

\begin{tabular}{|l|l|}
\hline \multicolumn{1}{|c|}{ Blackboard } & \multicolumn{1}{c|}{ Moodle } \\
\hline Discussion Board & Forum \\
\hline Student homepage & Profile page \\
\hline Staff information & Profile page \\
\hline External links & Add a resource: link to a file or website \\
\hline Can use course cartridges & Can use course cartridges in Moodle and Blackboard v6 format \\
\hline Pool manager & Questions \\
\hline Announcements & News forum \\
\hline Digital dropbox & Add an activity: advanced uploading of files \\
\hline
\end{tabular}

As the CAFÉ director held workshops, the similarities were stressed by first introducing a Moodle component using the equivalent Blackboard name and then reminding the attendees what the corresponding Moodle name was for the component. This appeared to help faculty transfer their knowledge of what the component was in Blackboard and how they might use that component in Moodle. From the perspective of a faculty attendee of those workshops, the second author of this paper appreciated the linkages. The linkages helped to both lessen the stress of learning an entire new system and speed up the course modifications of previous semesters' materials that would roll over into the new CMS.

\section{Update and Educate Key Faculty Committees Even before the System Is Available for Early Adopters}

This action takes very little time. By identifying key committees, such as distance learning committees, whose membership is often filled with fairly early adopters of new technology, an IS/IT person involved in putting the new system in place and making it operational can provide insight into some of the similarities and differences and get some of the technology leaders intrigued with exploring the capabilities of the new software. These faculty are likely those that have self-confidence in their ability to learn new software and use it effectively on the job. This can contribute to easing anxiety of others in the institution.

Members of the Academic Council were notified in October, 2010, that the full conversion to Moodle would occur in summer 2012. At this time the academic deans were encouraged to inform their faculty of the upcoming changes. During the January 2011 meeting of the Distance Learning Advisory Committee, members were instructed on how to access the Moodle Sandbox test site.

\section{Create Help Sheets for Popular Tasks}

In order to serve the entire faculty, along with some staff members, a quick and clear response to their questions was needed. Before the faculty began "playing in the Sandbox," help sheets for the most common activities were created. Using ScreenHunter, a free screen capture download (http://wisdomsoft.com/products/screenhunter free.htm), step-by-step directions were created in Microsoft Word. Using twocolumn tables in the landscape mode, screen captures were placed in the left column with explanatory text/directions being placed in the matching right column. The sheets were saved in both docx and PDF formats. This help-sheet creation process was quick yet effective as visual learners could both see the step illustrated and read instructions, while others not needing screen shots quickly read instructions on how to complete their tasks. The PDF sheets were sent out as a response to email and phone requests for help.

From the CAFÉ director's perspective of being a one-person shop to support faculty and staff during the conversion, the return on investment in terms of time spent to create the help sheets was tremendous. When someone would call or email for help, being able to send out a help sheet quickly allowed the support person to move on to the next problem in a timely manner. From the general faculty member's perspective, calling or emailing a request of "do 


\section{Issues in Information Systems}

Volume 13, Issue 2, pp. 209-218, 2012

you have a sheet on..." and hearing an immediate answer of "yes" or a quick email message with the attached sheet has been very positive. This allows the faculty member to keep progressing within his/her time allocated for working with the CMS on any given day. Also, based on personal experience, if no sheet was available, one was sure to follow within a fairly short timeline. The sheets were also sent out and posted to the Moodle for Instructors site.

\section{Create a Moodle Course Section that Contains Help Sheets}

As faculty began training in the Sandbox, a listing of the created help sheets was added to the Sandbox for access by the faculty. Once the move to the Production server began, a "Moodle for Instructors" section was created. In this section, both Moodle and non-Moodle resources were listed. Faculty wanting to have access to the help sheets had to request admittance to the section. This was handled a little differently than with Blackboard, the previous CMS. Previously all instructors were placed in the Blackboard User Group section. Over time, the Blackboard section became very large and cumbersome during system backups. Because of this, a decision was made to only add faculty to the Moodle for Instructors section if the faculty requested admittance. A screenshot of the Moodle for Instructors section is displayed in Figure 1. This provided yet another way for instructors to customize their level of Moodle support they felt they needed, without forcing it on anyone. As new help sheets were created, they were uploaded into the section. The sheets were grouped together by category-activity, general information, grades, new semester preparation, resource, etc. A partial listing of the available documents is displayed in Figure 2.

From the CAFÉ director's experience, numerous faculty members reported that having access to all the help sheets in one place was a big help for them, especially when working on their courses at odd hours of the night or weekends. In addition, they could quickly reference a help sheet when one of their colleagues had questions about Moodle. As a general faculty member, the second author of this paper definitely found the help sheets to be of benefit and referred quite a number of other faculty to them as faculty "came on board" with Moodle in following semesters.

Figure 1. Moodle for Instructors Section

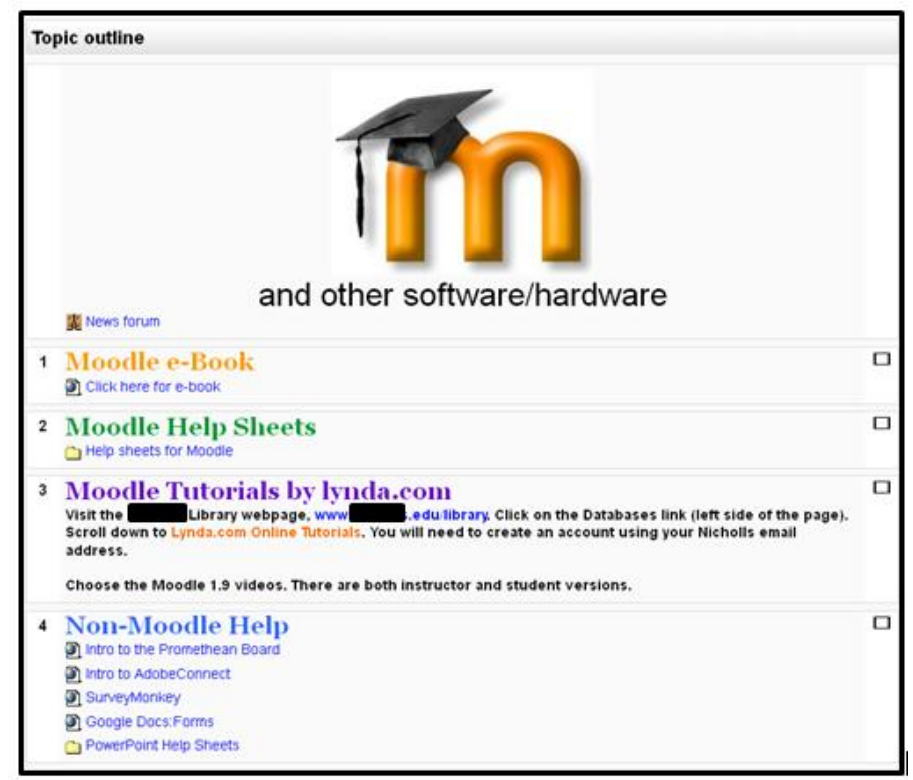




\section{Issues in Information Systems}

Volume 13, Issue 2, pp. 209-218, 2012

Figure 2. Partial Listing of Available Help Sheets

\begin{tabular}{|c|c|c|}
\hline Name & Size & Modified \\
\hline 园 ACTIVITY_--_Adding_a_Turnitin_activity_to_your_course.pdf & $303.5 \mathrm{~KB}$ & 23 March $2012,10: 36$ AM \\
\hline ש ACTIVITY_-_Assignment_Types.pdf & $284.1 \mathrm{~KB}$ & 23 February $2012,10: 20 \mathrm{AM}$ \\
\hline 은 ACTIVITY_--_Assignment_advanced_uploading_of_files.pdf & $376.4 \mathrm{~KB}$ & 26 July $2011,02: 13 \mathrm{PM}$ \\
\hline च ACTIVITY_-_-Deleting_a_quiz_attempt.pdf & $306.2 \mathrm{~KB}$ & 28 February 2012, 11:32 AM \\
\hline 园 ACTIVITY_-_Deleting_an_assignment.pdf & $279.1 \mathrm{~KB}$ & 28 February $2012,11: 32$ AM \\
\hline 园 ACTIVITY_--_Insert_a_forum.pdf & $431.9 \mathrm{~KB}$ & 3 May $2011,11: 13$ AM \\
\hline ¿ ACTIVITY_-_QQuiz_settings.pdf & $422.5 \mathrm{~KB}$ & 26 July $2011,04: 27$ PM \\
\hline 园 ACTIVITY_--_Random_questions_for_your_quiz.pdf & $325.4 \mathrm{~KB}$ & 5 January $2012,01: 12 \mathrm{PM}$ \\
\hline च ACTIVITY_--_Shuffling_questions_or_within_questions_in_a_quiz.pdf & $308.9 \mathrm{~KB}$ & 5 January 2012, 08:00 AM \\
\hline ح ADMINISTRATION_--_Creating_Groups.pdf & $353.8 \mathrm{~KB}$ & 8 February $2012,10: 39 \mathrm{AM}$ \\
\hline Bb_to_MOODLE_-__Blackboard_to_Moodle_conversion_info.pdf & $312.9 \mathrm{~KB}$ & 3 May $2011,03: 59 \mathrm{PM}$ \\
\hline ه Bb_to_MOODLE_--_Converting_a_test_pool_from_Bb_to_Moodle.pdf & $633.3 \mathrm{~KB}$ & 16 June 2011, 03:25 PM \\
\hline 国 GENERAL_INFO_--_Adding-restoring_tool_blocks.pdf & $325.7 \mathrm{~KB}$ & 22 August 2011, 09:57 AM \\
\hline ح GENERAL_INFO_--_Adding_an_attachment_to_text_in_a_text_box.pdf & $340.6 \mathrm{~KB}$ & 15 November 2011, 12:54 PM \\
\hline च GENERAL_INFO_--_Administration_block.pdf & $272.8 \mathrm{~KB}$ & 27 April $2011,01: 40$ PM \\
\hline 园 GENERAL_INFO_--_Assign_roles.pdf & $371.7 \mathrm{~KB}$ & 9 August $2011,10: 08$ AM \\
\hline 园 GENERAL_INFO_--_Combining_students_from_multiple_sections_into_one.pdf & $679.8 \mathrm{~KB}$ & 16 August $2011,08: 44$ AM \\
\hline च GENERAL_INFO_--_Edit_your_profile.pdf & $464.8 \mathrm{~KB}$ & 27 April 2011, 10:33 AM \\
\hline 园 GENERAL_INFO_--_Insert_an_image.pdf & $440.2 \mathrm{~KB}$ & 27 April 2011, 11:48 AM \\
\hline ح GRADES_-_Adding_a_grade_ttem.pdf & $373.5 \mathrm{~KB}$ & 13 January $2012,09: 08$ AM \\
\hline
\end{tabular}

\section{Offer Workshops in the Semester Prior to Implementation}

In the semester prior to beginning the move to Moodle, workshops were offered at various times of the day and days of the week. The workshops contained the most pertinent information that the faculty would need to begin creating their Moodle sections. This included how to load resources into the section, how to group the resources together into directories, how to set up assignments, and how to set up forums. The most attended sessions were the ones held during finals week; these workshops were the last thing the faculty did before leaving at the end of the spring semester. Additional workshops were held over the summer as well, for those who may not have attended the May workshops.

The CAFÉ director observed that faculty reported seeing the software and being able to "play" with the software eased their minds about the conversion. Some admitted to being adverse to technology changes, but having the time to slowly convert their courses across from Blackboard to Moodle relieved their stress levels. From a general faculty member's perspective, being able to have the training offered both at end of spring semester and in the summer allowed for flexibility. By being able to choose the timeframe that would better match the actual experimentation and preparation time the faculty member would experience, the training was of more value than one-time-only offerings.

\section{Pilot Moodle with Volunteers}

Both Moodle and Blackboard were available in the fall 2011 semester. However, early adopters on campus had been contacted and encouraged to pilot at least one of their courses in Moodle. These early adopters were identified through historical records of length of time they had used Blackboard and/or previous involvement offering online courses. During Fall 2011, a total of 1297 course sections were offered at the university. Of these sections, 394 sections were created and contained content in Moodle. Table 2 displays the number of courses offered, broken down by college, and a listing of how many of these course sections were converted to Moodle. Overall, about $30 \%$ of all class sections campus-wide were moved to Moodle. The College of Arts and Sciences had 30\% of their class sections in Moodle while 31\% of the class sections in the College of Business were in Moodle. The College of Education had $18 \%$ of their class sections in Moodle, and University College also had $18 \%$ of their sections in Moodle. The largest conversion came from the College of Nursing and Allied Health, where $70 \%$ of their class sections were in Moodle. 


\section{Issues in Information Systems}

Volume 13, Issue 2, pp. 209-218, 2012

Table 2. Course Section Count by College

\begin{tabular}{|l|c|c|c|}
\hline \multicolumn{1}{|c|}{ College } & Sections Offered & Sections in Moodle & \% in Moodle \\
\hline Arts and Sciences & 748 & 225 & $30 \%$ \\
\hline Business & 125 & 39 & $31 \%$ \\
\hline Education & 190 & 39 & $21 \%$ \\
\hline Nursing and Allied Health & 94 & 66 & $70 \%$ \\
\hline University College & 140 & 25 & $18 \%$ \\
\hline Campus total & 1297 & 394 & $30 \%$ \\
\hline
\end{tabular}

In the past, the Nursing Department had been involved in embracing new technologies presented. The department was one of the first departments to use Blackboard to its fullest potential. As seen in the data presented, once again this college took the lead in the early adopters. The percentage of courses in Moodle from each college was also reassuring, as early adopters were spread throughout the various colleges of the university. This ensured that those slower to adopt the new CMS would find colleagues who already had experience with Moodle who could assist with quick one-on-one assistance when needed.

Having the early adopter group to test out the different activities and resources was a big help to the instructional support CAFÉ director. Early on, problems with grading occurred and were easily resolved with the small number of sections in Moodle. From the perspective of a general faculty member who conducted her online course fully in Moodle in fall of 2011, this smaller number of faculty involved (as opposed to the entire faculty) meant quicker research by the CAFÉ director if a problem did arise.

\section{Trouble-Shoot and Solve Problems in a Timely Manner}

Frustration occurred when a teacher could not solve a problem he/she was experiencing. When problems were reported, the previously created help sheets were sent out immediately to help the faculty. If the problem was something that had not been previously encountered, a search for a solution was begun usually starting with a Google search of the condition or error message. If a solution was not found by the second day, the faculty member was contacted to let him/her know a solution was being pursued.

As a faculty member herself, the CAFÉ director recognizes that nothing is more frustrating than wondering if your problem has been forgotten or put to the side. Anecdotal evidence through faculty feedback showed that this acknowledgment of second day "still researching the problem" was appreciated by faculty, who knew their issues were not just being abandoned. From a general faculty member's personal perspective, keeping faculty in the loop of what was happening led to more patient faculty (and students).

\section{Create Additional Help Sheets as Problems Arise}

As the semester progressed, additional help sheets were created as faculty needed help or resolution of a problem. For example, at midterm a faculty member reported the course total column was not computing grades. During an investigation of the problem, it was determined that the faculty member inadvertently keyed in grades in the course total column. As a result, the column was labeled as "overridden" and would no longer compute the grades. A help sheet was immediately created and sent out to all faculty. Knowing that other faculty might have overridden the grade column, an email on how to recognize the problem along with the new help sheet on how to resolve the problem was sent out prior to the end of the semester. This proactive approach was appreciated by other faculty.

The CAFÉ director found that as one semester ended and another started, faculty began to venture and try new things in Moodle, thus the need for additional help sheets. Some problems did not arise during the initial semester 


\section{Issues in Information Systems}

Volume 13, Issue 2, pp. 209-218, 2012

of volunteer usage. When they occurred during the next semester, having new help sheets to send out to all the faculty was a big help. In addition, as Moodle add-ons/plugins/blocks were added to the production server, faculty requested help sheets for these new components. Currently, some faculty are venturing out and are creating help sheets of their own. These "faculty created" help sheets are being included in the Moodle for Instructors section. From a general faculty member's perspective, the continued additions of more help sheets may eliminate the need for additional structured workshops that might otherwise be at an inconvenient time.

\section{Send out Email with Help Sheet Attachments of Beginning-of-Semester and End-of-Semester Tasks}

On the first day of the semester when faculty returned to their offices, the CAFÉ director sent an email with attachments containing common beginning-of-semester tasks help sheets to both faculty and staff. The sheets included the following "How to's": 1) insert a label, 2) add a file (syllabus), 3) display a directory, 4) add an assignment, 5) set up a forum, 6) add additional weeks/topics, and 7) assign roles. At the end of the semester, an email was sent out containing attachments of other help sheets. The sheets included the following "How to's": 1) backup your course, 2) restore your course, 3) correct category/course totals, and 4) export your grade book.

The CAFÉ director documented that she received several thank-you emails because of these actions. Faculty appreciated having most of the necessary steps needed to get their courses going in one location. From a general faculty perspective, it is nice to be reminded (with helpful attachments) to speed preparations for the next semester.

\section{Offer Small-Group Help with Grades at Mid-Term and End-of-Semester}

Some faculty needed help with computing their students' grades. Since most faculty have their own way of computing the end-of-course grade, small group help (no more than 3 people at a time) was offered. For two weeks prior to mid-term and again at the end of the semester, one-hour sessions on grade computation help were available to faculty. Using Google Docs, a link to a registration spreadsheet was sent out to faculty to eliminate phone calls and streamline the registration process. A sample of the registration form is displayed in figure 3.

The CAFÉ director observed that by using a small group format, there was minimal confusion experienced by faculty in attendance. Also, the wait time for help as the support person moved from one faculty member to another was minimal. From a general faculty member's perspective, this small group format was much more productive than large workshops of 10 or more people that had been conducted by other trainers several years earlier when the university first implemented Blackboard CMS. When larger attendance workshops had been used, it was not unusual for an instructor to return to his or her office disappointed that no insight was gained on customizing the grading for his/her class.

Figure 3. Moodle Grades Registration

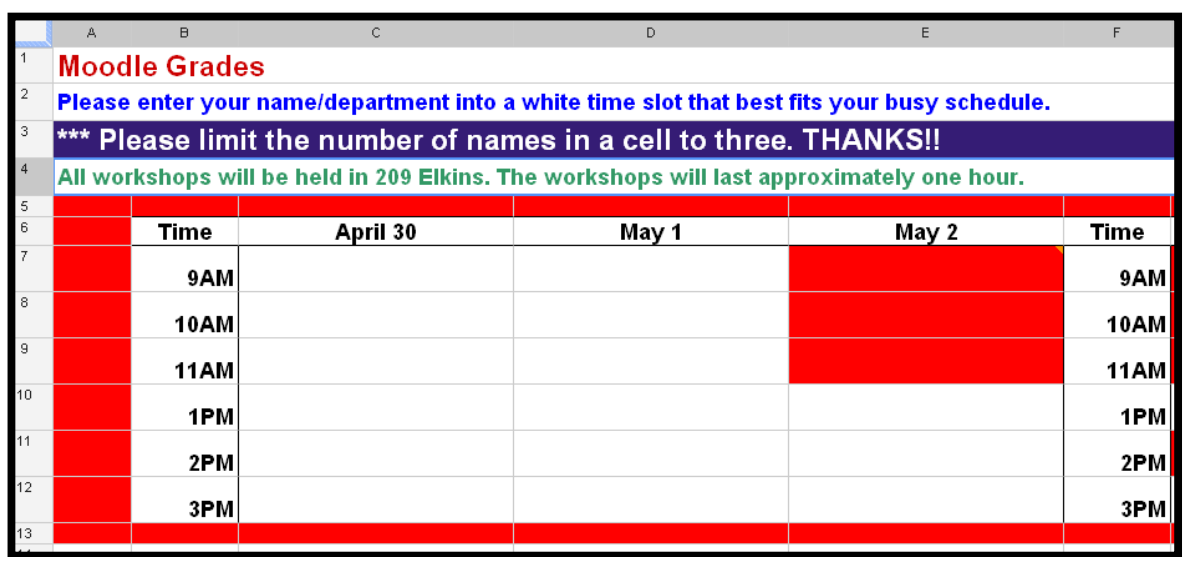




\section{Issues in Information Systems}

Volume 13, Issue 2, pp. 209-218, 2012

\section{Reiterate to Faculty to Export Moodle Grades to a Spreadsheet such as Excel to Check Grade Calculations before Assigning Final Grades for the Term}

While some faculty members were routinely exporting Moodle grades to a spreadsheet for backup grades or first entering grades in a spreadsheet and then uploading them to Moodle, $100 \%$ of the instructors were not doing this. As can happen in end user development activities, formulas could be incorrect, and without another faculty checking the instructor's design, incorrect final grade outputs could result. Thus after experiencing a second round of Moodle adopters in the spring 2012 semester and their concerns at the end of the semester, the authors have added this step to the list of successful conversion activities.

The CAFÉ director observed that for two days after grades were due, faculty members were panicking over their computed grades. For some faculty, their stress was for naught; the student(s) reporting the problem had incorrectly computed their grades. For others, grade changes had to be made, causing the University Registrar to add Moodle to his list of why faculty can't compute grades. From the perspective of a business faculty member, faculty in that college typically continued to calculate grades in an Excel spreadsheet to confirm correct calculations and used the Excel spreadsheet calculations as a basis for official grade recording. The CAFÉ director now routinely suggests that faculty maintain Excel spreadsheets to help ensure correct grade calculations.

\section{Remain Courteous, Jovial, and Accepting of Faculty Thanks}

This final point reflects the specific thoughts of the CAFÉ director, who prepared all the help sheets, conducted workshops, etc. Throughout the conversion, keeping a smile on her face and a good attitude helped bring calmness to the faculty. Faculty members were frustrated during the conversion, especially since this was the fourth major software/system change on campus within two years. Especially for late adopters, this was stressful. So being pleasant and helpful to faculty was rewarding to both parties involved. As emails arrived thanking her for her help, she saved them, putting them in a folder for possible future use, even if the use is just to read them again as a "pick me up." In addition, from the CAFÉ director's viewpoint, receiving this gratitude made all the trying times worth the time and effort put into the conversion. This was especially true when the person offering the appreciation was extremely difficult and obnoxious about the conversion.

Finally, from the perspective of the second author, a general faculty member, the CAFÉ director's attitude was critical. Her ability to remain courteous and offer a smile when communicating with a frustrated Moodle user was experienced first-hand. Her approach of always listening calmly, giving suggestions, and following through with communications and research did indeed lessen frustration. At the end of the day and with a solution to the issue, that courtesy and enthusiasm was "priceless."

\section{CONCLUSIONS}

Changing Course Management Systems at a university is a significant IS/IT change. Using what has been learned over the years from the Technology Acceptance Model literature, as well as organizational change and change management literature, the authors' university accomplished this major conversion in a year's time on a "shoestring" budget. While each institution is indeed different, the strategies offered in this paper illustrate that even though the budget is low related to faculty support for the conversion process, a successful conversion can occur.

By determining similarities and differences between the old and new system and educating key faculty committees even before implementation, the early adopters can start "buying in" to the change. Creating help sheets that are useful for both visual and text learners and ready exactly when needed by an individual faculty member can lessen frustration. Of course running parallel software for a period of time allows early adopters to work with the new system and help identify the need for additional topic/task help sheets. Timely trouble shooting and feedback, 


\section{Issues in Information Systems}

Volume 13, Issue 2, pp. 209-218, 2012

specific workshops at midterm and finals time, and courteous, smiling faces all contribute to a successful conversion.

\section{REFERENCES}

1. Agarwal, R., \& Prasad, J. (1997). The role of innovation characteristics and perceived voluntariness in the acceptance of information technologies. Decision Sciences, 28(3), 557-582.

2. Baker-Eveleth, L., \& Stone, R. (2008). Expectancy theory and behavioral intentions to use computer applications, Interdisciplinary Journal of Information, Knowledge, and Management, 3, 135-146.

3. Brown, S. (2009). Technology acceptance and organizational change: An integration of Theory. Dissertation: Auburn University, Auburn, Alabama.

4. Chang, T., Lin, H., \& Song, M. (2011). University faculty members' perceptions of their teaching efficacy. Innovations in Education and Teaching International, 48(1), 49-60

5. Davis, F. D., (1989). Perceived usefulness, perceived ease of use, and user acceptance of information technology. MIS Quarterly, 13(3), 319-339.

6. Davis, F. D., Bagozzi, R.P., and Warsha, P. R. (1989). User acceptance of computer technology: A comparison of two theoretical models. Management Science, 35(8), 982-1002.

7. Fedorowicz, J., Gelinas, U., Usoff, C., \& Hachey, G. (2005). Twelve tips for successfully integrating enterprise systems across the curriculum. Journal of Information Systems Education, 15(3), 235-244.

8. Halawi, L., \& McCarthy, R. (2007). Measuring faculty perceptions of Blackboard using the Technology Acceptance Model. Issues in Information Systems, 8(2), 160-165.

9. Lee, J. A., \& Busch, P. E. (2005). Factors related to instructors' willingness to participate in distance education. Journal of Educational Research, 99(2), 109-115.

10. Orr, R., Williams, M., \& Pennington, K. (2009). Institutional efforts to support faculty in online teaching. Innovative Higher Education, 34, 256-268.

11. Schepers, J., \& Wetzels, M. (2006). A meta-analysis of the technology acceptance model: Investigating subjective norm and moderation effects. Information and Management, 44, 90-103.

12. Tabata, L., \& Johnsrud, L. (2008). The impact of faculty attitudes toward technology, distance education, and innovation. Research in Higher Education, 49, pp. 625-646.

13. Venkatesh, V. (1999). Creation of favorable user perceptions: Exploring the role of intrinsic motivation. MIS Quarterly, 23(2), 239-260.

14. White, J., \& Myers, S. (2001). You can teach an old dog new tricks: The faculty's role in technology implementation. Business Communication Quarterly, 64(3), 95-100. 